\title{
Chromosomal aberrations induced in bone marrow cells of mice due to the administration of the non- steroidal anti-inflammatory drug, Piroxicam
}

\author{
Mohamed A. Dkhil ${ }^{1,2 \star}$ Amany Tohamy ${ }^{1}$ and Mohamed S. Gabry ${ }^{1}$ \\ ${ }^{1}$ Department of Zoology and Entomology, Faculty of science, Helwan University, Egypt. \\ ${ }^{2}$ Department of Zoology, College of Science, King Saud University, Riyadh, Saudi Arabia.
}

Accepted 13 January, 2011

\begin{abstract}
Cytogenetic changes in male albino mice due to the effect of the non-steroidal anti-inflammatory drug, Piroxicam was investigated after daily intraperitoneal injection with $0.3 \mathrm{mg} / \mathrm{kg}$ body weight, for $1,2,3$ and 4 weeks. The observed structural chromosomal aberrations were in the form of chromatid breakage, centric fusion, centromeric attenuation, ring chromosome and end to end association. At all the treatment periods used the number of cells with chromatid breakages and with total structural aberrations increased to statistically significant levels. Only after one and four weeks of treatment it was noticed that the number of cells with end to end association increased significantly. No significant changes in the mitotic indicies could be detected in all mice groups. The study demonstrated that Piroxicam affects the bone marrow cells where it causes some aberrations in the chromosomes. Thus, Piroxicam should be used under strict medical control, and these serious side effects should be considered and taken in consideration when using Piroxicam in treatments.
\end{abstract}

Key words: Cytogenecity, chromosomes, Piroxicam.

\section{INTRODUCTION}

The prevention and treatment of rheumatic diseases now ranks as one of the most challenges facing those concerned with public health problems. For this purpose, a variety of anti-inflammatory drugs, belonging to different chemical classes, have been introduced for clinical use as anti-rheumatics. The non-steroidal anti-inflammatory drugs (NSAIDs) comprise one of the several families of chemical agents with clinically useful anti-inflammatory and analgesic properties (Sekiguchi et al., 2008).

These NSAIDs become one of the most commonly prescribed drugs in the physician's ornamentarium (Levin, 1988). The analgesic and anti-pyretic properties of these drugs makes their use widely spread. Also, these drugs are usually taken for a relatively long periods of time.

${ }^{\star}$ Corresponding author. E-mail: mohameddkhil@yahoo.com. Tel: 00966-14675754. Fax: 00966-14678514
Although NSAIDs are effective in the treatment of a variety of acute and chronic pain conditions, their use has been associated with the induction of gastric injury, which is the most common adverse effect (Bulbena et al., 1993).

Numerous environmental and industrial chemicals are capable of causing cytogenetic damage in experimental animals. The potential for similar effects in man is obvious. Since cytogenetic damage is generally associated with severe clinical disorder (Burns, 1972; Riccardi, 1977), it is imperative to determine if chemicals to which man may be exposed are capable of inducing this type of genetic damage.

It is known that many substances with an antiinflammatory action influence DNA metabolism (Klein and Woltawa, 1975; Hoffer and Thumb, 1984) and can thus give rise to latter damage in the genetic material. Since non-steroidal anti-rheumatic drugs are usually administered over long periods, appraisal of the mutagenic risk of these drugs would appear to be especially 


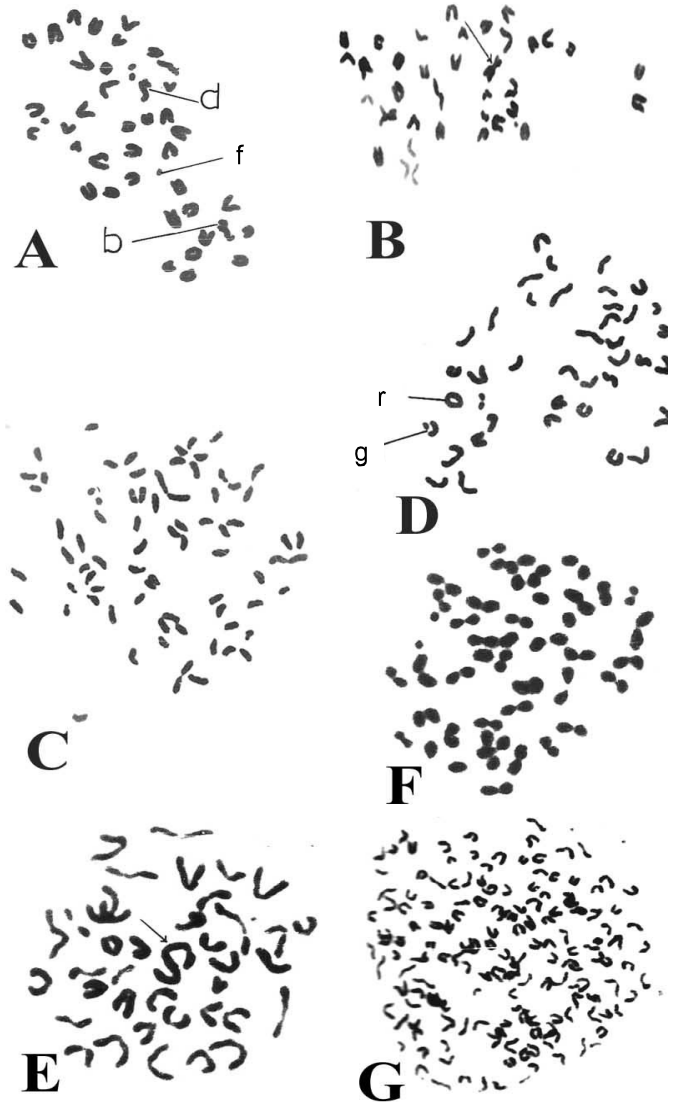

Figure 1. A photomicrograph of metaphase spreading from mouse bone marrow. (A) Chromatid break (b) terminal deletion (d) and fragmented chromosome (f). (B) Centric fusion. (C) Centromeric attenuation. (D) Ring chromosomes (r) and gap (g). (E) End to end association (arrow). (F) Endomitosis; (G) Polyploidy.

\section{important.}

The current study aimed to investigate the cytogenetic damage induced in bone marrow cells of mice treated with the NSAID Piroxicam.

\section{MATERIALS AND METHODS}

\section{Experimental animals}

Healthy adult male mice (Mus musculus) approximately 3 to 5 months old ranging in weight from 20 to $25 \mathrm{~g}$, purchased from the Research Institute of Ophthalmology, Giza, Egypt were used in the present investigation. Animals were housed in specially designed cages and were kept in the laboratory under constant conditions for at least one week before use. They were fed a standard commercial diet. The experiments were approved by the state authorities and followed Egyptian rules on animal protection.

\section{Experimental design}

Thirty two animals were used for cytogenetic studies; the animals were divided into 5 groups (one control group of 12 animals and four treated groups (Group 1, Group 2, Group 3 and Group 4) of five animals each. Each treated group was daily intraperitoneally injected with $0.3 \mathrm{mg} / \mathrm{kg} /$ day Piroxicam (Pfizer, Egypt) for one, two, three, and four weeks respectively. The negative control group was injected with the same volume of distilled water used in the treated animals. After one, two, three, and four weeks a group of mice (3 control and 5 treated) was sacrificed $24 \mathrm{~h}$ after the last injection.

\section{Chromosomal preparations}

The method used for obtaining chromosome preparations from the bone marrow cells was based on the technique used by Yosida and Amans (1965) with some modifications. In brief; the animals were injected with $0.5 \mathrm{mg} / \mathrm{kg}$ Colchicine $2 \mathrm{~h}$ before killing, this was done whether the animal was treated with the drug or acted as control. The animals were killed by cervical dislocation and both femora were immediately removed and the metaphase spreads were prepared from the bone marrow. Chromosomes were stained in phosphate buffered Giemsa.

\section{Metaphase scoring}

Per animal, 50 metaphase spreads were examined microscopically for chromosomal aberrations. Only cells with well spread chromosomes were selected for scoring. All metaphase spreads, were examined for both structural and numerical aberration (John, 1973).

\section{Mitotic index}

The number of dividing cells, including late prophases and metaphases (3000 cells/animal) were counted. The mitotic index was calculated as the number of dividing cells $/ 1000$ cell/ animal.

\section{Statistical analysis}

The data obtained were statistically analyzed using a $2 \times 2$ contingency table $\left(X^{2}\right)$ (Sokal and Rohlf, 1981).

\section{RESULTS}

Structural chromosomal aberrations observed in the present study were in the form of chromatid breakage [deletions, breaks, fragments, and gaps (Figures 1A, B, and D)], centric fusions (Figure1B), centromeric attenuations (Figure 1C), rings (Figure 1D) and end to end associations (Figure 1E). A cell was considered centromerically attenuated when it contains at least three chromosomes with centromeric split. The observed numerical chromosomal aberrations were in the form of endomitosis (Figure 1F) and polyploidy (Figure 1G).

Table (1) represents the data obtained after daily treatment with Piroxicam $(0.3 \mathrm{mg} / \mathrm{kg})$ for one, two, three and four weeks. Significant increase (at $P<0.05)$ was observed in the number of chromatid breakages and end to end associations.

Also, the total number of structural chromosomal aberrations increased significantly $($ at $\mathrm{P}<0.005)$ in the treated group when compared with that of the control 
Table 1. Structural chromosomal aberrations induced in mice bone marrow cells after treatment with piroxicam $(0.3 \mathrm{mg} / \mathrm{kg})$ for different periods of time. ( $\mathrm{n}=5)$.

\begin{tabular}{|c|c|c|c|c|c|c|c|c|c|c|c|c|}
\hline \multirow{2}{*}{ Type of aberrations } & \multicolumn{3}{|c|}{ Group 1} & \multicolumn{3}{|c|}{ Group 2} & \multicolumn{3}{|c|}{ Group 3} & \multicolumn{3}{|c|}{ Group 4} \\
\hline & C & $\mathbf{T}$ & $x^{2}$ & C & $\mathbf{T}$ & $\mathrm{X}^{2}$ & C & $\mathbf{T}$ & $\mathrm{x}^{2}$ & C & $\mathbf{T}$ & $\mathrm{x}^{2}$ \\
\hline Chromatid breakage & $1 \pm 0.0$ & $3.4 \pm 1.6$ & $4.87^{*}$ & $0.67 \pm 05$ & $3.20 \pm 0.8$ & $3.88^{*}$ & $0.67 \pm 0.6$ & $3.20 \pm 0.80$ & $5.59^{* *}$ & $1.00 \pm 1.0$ & $4.20 \pm 1.4$ & $6.81^{* *}$ \\
\hline Centric fusion & - & $0.6 \pm 0.8$ & 2.41 & $0.33 \pm 0.6$ & $1.4 \pm 0.6$ & 2.14 & $1.7 \pm 0.6$ & $2.0 \pm 1.0$ & 0.11 & $0.3 \pm 0.4$ & $1.4 \pm 1.1$ & 2.14 \\
\hline Centromeric attenuation & $1.3 \pm 0.6$ & $1.8 \pm 0.8$ & 0.27 & $1.0 \pm 1.0$ & $0.4 \pm 0.5$ & 1.09 & $1.3 \pm 0.5$ & $1.0 \pm 1.0$ & 0.18 & $1.3 \pm 0.6$ & $1.6 \pm 1.5$ & 0.10 \\
\hline Ring Chromosome & $0.3 \pm 0.6$ & $0.6 \pm 0.6$ & 0.42 & - & $1.0 \pm 1.0$ & 3.01 & $0.3 \pm 0.6$ & $1.2 \pm 1.3$ & 1.62 & $0.3 \pm 0.5$ & $0.8 \pm 1.8$ & 0.67 \\
\hline End to end association & - & $1.4 \pm 1.0$ & $4.21^{*}$ & - & $0.4 \pm 0.5$ & 1.21 & - & $0.8 \pm 0.8$ & 2.42 & - & $1.6 \pm 1.5$ & $4.90^{*}$ \\
\hline
\end{tabular}

Data are Means $\pm S D$. * Significant at $p<0.05,{ }^{* *}$ Significant at $p<0.01$. C, control group; T, treated group.

group after one week of treatment (Figure 2). In the treated group, the increase in the number of numerical chromosomal aberrations did not reach a statistically significant level when compared with that of the control group.

Daily injection of the animals for two weeks resulted in the induction of significant number of chromatid breakages (at $\mathrm{P}<0.05$ ) and of total structural aberrations (Figure 2). Again, no significant increase in the number of numerical chromosomal aberrations could be detected (Table 1).

In the group of animals treated daily with Piroxicam for three weeks, significant increase (at $P<0.01)$ was observed in the number of chromatid breakage and total structural aberrations (Table 1, Figure 2). No significant differences were recorded in the number of numerical aberrations between treated and control groups (Table 2).

Data were obtained after daily injection with Piroxicam for four weeks. The number of chromatid breakages increased significantly (at $P<0.01$ ), while the increase in the number of end to end associations was found to be significant (at $P<0.05$ ). However, the increase in the number of total structural aberrations (Figure 2) reached a highly significance (at $\mathrm{P}<0.005)$. No significant change in the number of numerical aberrations could be detected.

No significant changes in the mitotic indicies could be detected between the control groups and the different groups treated with Piroxicam for the different periods of treatment used in the present study (Table 3 ).

\section{DISCUSSION AND CONCLUSION}

In the present investigation an increase in the structural chromosomal aberrations was observed in the four groups of animals sacrificed after the different periods of treatments used (one, two, three and four weeks). The significant chromosomal aberrations observed were mainly in the form of chromatid breakages (deletion, gap, break and fragments). Damage to chromosomes after the $G_{1}$ stage of the cell cycle causes chromatid lesions only, and results in chromatid breakage (Moore, 1981; Febrer et al., 2008). Therefore, it may be possible to conclude that Piroxicam exerts its clastogenic effect after the G1 stage of the cell cycle.

The number of cells with end to end associations increased significantly only in the two groups treated for one and four weeks. Accordingly, this type of aberration after four weeks of treatment as an indicator of the cumulative effect of Piroxicam.

Again, only in the two groups treated for one and four weeks, the number of cells with centromerically attenuated chromosomes increased slightly over the control level. This slight increase did not reach a statistically significant level. Centromeric attenuation, example, splitting of the centromere without mitosis, may be an early stage of endomitosis, in which case it gives rise to polyploidy (De Hondet et al., 1983; Ito and Matsumoto, 2010).

In the present study, polyploidy was rare, the centromeric attenuation is therefore most likely an experession of non-specific cytotoxicity. Dolara et al. (1994) described the same phenomenon of chromatid separation under the name "nonsynchronous centromeric separation" and concluded that the disturbances of the spindle filaments are likely to be the cause of the disruption of the centromeric apparatus during mitosis, which manifests itself as a chromatid separation. The slight non-significant increase in centromerically attenuated cells observed in the present work may lead to the conclusion that Piroxicam has no effect on the spindle apparatus. Disturbance of the spindle apparatus is a suggested mechanism for polyploidy. The rare 


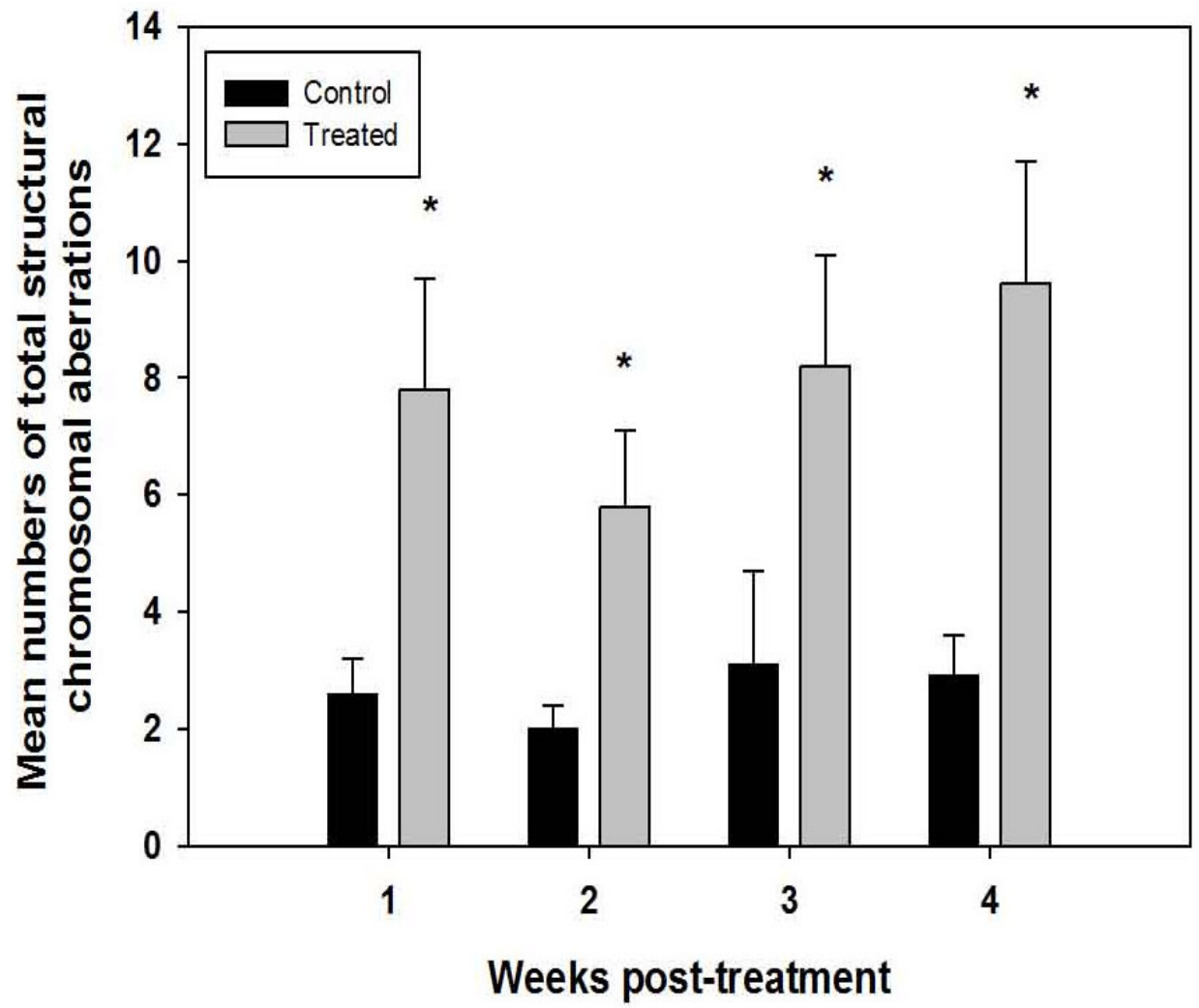

Figure 2. Total structural chromosomal aberrations induced in mice bone marrow cells posttreated with piroxicam. ${ }^{*}$ Value of $\mathrm{P}<0.05$ were considered statistically significant.

Table 2. Numerical chromosomal aberrations induced in mice bone marrow cells after treatment with piroxicam $(0.3 \mathrm{mg} / \mathrm{kg})$ for different periods of time. $(n=5)$.

\begin{tabular}{|c|c|c|c|c|c|c|c|c|c|c|c|c|}
\hline \multirow{2}{*}{$\begin{array}{l}\text { Types of } \\
\text { aberrations }\end{array}$} & \multicolumn{3}{|c|}{ Group 1} & \multicolumn{3}{|c|}{ Group 2} & \multicolumn{3}{|c|}{ Group 3} & \multicolumn{3}{|c|}{ Group 4} \\
\hline & C & $\mathbf{T}$ & $\mathrm{x}^{2}$ & C & $T$ & $\mathrm{X}^{2}$ & C & $\mathrm{T}$ & $\mathrm{X}^{2}$ & C & $\mathbf{T}$ & $\mathrm{X}^{2}$ \\
\hline Endomitosis & - & $0.8 \pm 1.3$ & 2.41 & $0.3 \pm 0.6$ & $0.4 \pm 0.5$ & 0.02 & - & - & & - & - & - \\
\hline Polyploidy & - & $0.2 \pm 0.4$ & 0.60 & t & $0.6 \pm 0.5$ & 2.41 & $0.3 \pm 0.5$ & $0.2 \pm 0.4$ & 0.13 & - & $1.4 \pm 0.5$ & 1.21 \\
\hline $\begin{array}{l}\text { Total numerical } \\
\text { aberrations }\end{array}$ & - & $0.8 \pm 1.8$ & 2.42 & $0.3 \pm 0.6$ & $1.0 \pm 1.0$ & 1.121 & $0.3 \pm 0.5$ & $0.2 \pm 0.4$ & 0.13 & - & $1.4 \pm 0.5$ & 1.21 \\
\hline
\end{tabular}

The data are expressed in Mean \pm SD. C, control group; T, treated group.

number of polyploid cells observed in the present study which may support the concluded non-interaction between Piroxicam and the spindle apparatus.

The results of the present work showed that the number of aberrations/cell did not exceed one aberration/ cell and that the frequency of aberrant cells was 15.6, $11.6,16.4$ and $19.2 \%$ in the groups treated for one, two, three and four weeks respectively.

It was recorded that Piroxicam induces gastric ulcers by in rats exposed to restraint and hypothermic stress at $4{ }^{\circ} \mathrm{C}$ (Alsarra et al., 2010). Also, it increases colon tumorigenesis and promotes apoptosis in mice (Palmerini et al., 2007) and it induces bone marrow lymphopolesis (Hassanein et al., 2004).
But to our knowledge, based on several surveys, only two studies concerning the genotoxic effect of Piroxicam could be found. Kullich and Klein (1986) and Kullich et al. (1990) reported that cytogenetic investigations before and after therapeutic application of Piroxicam for two weeks did not reveal any change in sister chromatid exchange (SCE) levels. In addition, the frequency of SCEs was determined in human lymphocytes in vitro and in vivo after 14 days of treatment. Kullich et al. (1990) reported that there was no significant change in SCE levels which could be detected neither In vitro nor In vivo. The significant increase in chromosome breakages observed in the present study after treatment with the therapeutic dose of Piroxicam $(0.3 \mathrm{mg} / \mathrm{kg})$ for one, two, 
Table 3. Effect of treatment with piroxicam $(0.3 \mathrm{mg} / \mathrm{kg})$ on the mitotic index of mice bone marrow cells. $(\mathrm{n}=5)$.

\begin{tabular}{lcccc}
\hline \multirow{2}{*}{ Groups } & \multicolumn{4}{c}{ Number of dividing cells/1000 cell/animal } \\
\cline { 2 - 5 } & Group 1 & Group 2 & Group 3 & Group 4 \\
\hline Control & $20.00 \pm 1.00$ & $22.33 \pm 3.06$ & $17.67 \pm 1.53$ & $21.00 \pm 4.00$ \\
Treated & $21.60 \pm 1.14$ & $23.60 \pm 1.95$ & $21.20 \pm 1.92$ & $21.60 \pm 1.52$ \\
$X^{2}$ & 0.23 & 0.33 & 1.21 & 0.34 \\
\hline
\end{tabular}

The data are expressed in Mean \pm SD.

three and four weeks may add more support to the previously reported conclusion that the mechanism of SCE formation is different from that of chromosome aberrations and that SCEs represent, only a part of the total DNA damage (Wolff et al., 1977; Cavallo et al., 2006).

No significant change in the mitotic indices could be detected in the different groups treated with Piroxicam when compared with their comparable control groups. These results may indicate that Piroxicam did not interact with the spindle apparatus.

Most chromosomal aberrations are deleterious and result in cell death. However, some types (example, reciprocal translocations, small deletions, and inversions) can lead to alter gene function(s) without accompanying loss in cell viability. Alternation in gene function occurring as a result of several different kinds of cancer (Mitelman, 1983; Yoshida et al., 2008), indicating the probable involvement of chromosomal aberrations in carcinogenesis.

Consistent with this relationship, chromosomal aberrations are induced by many known mutagenes and/or carcinogenes (Preston et al., 1983; Kawauchi et al., 2010). These findings make chromo-somal aberration analysis a useful indicator of genotoxic/ cytotoxic damage in bone marrow cells following in vivo exposures to xenobiotics.

It is clear from the present study that the cytogenetic changes recorded during the present study may indicate the clastogenic potential of Piroxicam. These means that Piroxicam should be used under strict medical control and these serious side effects should be considered and taken in consideration when using Piroxicam in treatments.

\section{ACKNOWLEGDEMENTS}

This work was gratefully supported by the centre of Excellence for Biodiversity Research, College of Science, King Saud University, Riyadh, Saudi Arabia.

\section{REFERENCES}

Alsarra IA, Ahmed MO, Alanazi FK, Eltahir KE, Alsheikh AM, Neau SH (2010). Influence of cyclodextrin complexation with NSAIDs on NSAID/cold stress-induced gastric ulceration in rats. Int. J. Med. Sci.,
5: 232-239.

Bulbena O, Escolar G, Navarro C, Bravo L, Pfeiffer CJ (1993). Gastroprotective effect of zinc acexamate against damage induced by nonsteroidal anti-inflammatory drugs: A morphological study. Dig. Dis. Sci., 38: 730-739.

Burn SGW (1972). The Science of Genetics; An Introduction to Heredity, MacMillan, New York, pp. 211.

Cavallo D, Ursini CL, Bavazzano P, Cassinelli C, Frattini A, Perniconi B, Di Francesco A, Ciervo A, Rondinone B, Lavicoli S (2006). Sister chromatid exchange and oxidative DNA damage in paving workers exposed to PAHs. Ann. Occup. Hyg., 50: 211-28.

Handte De, HA, Fahmy AM, Abdelbaset SA (1983). Chromosomal and biochemical studies on the effect of Kat extract on laboratory rats. Degeberakuzatuib and phagocytosed lysosomes by Kupffer cell lysosomes. Lab. Invest., 48: 556-564.

Dolara P, Toricelli F, Antonelli W (1994). Cytogenetic effects on human lymphocytes of a mixture of fifteen pesticides commonly used in Italy. Mut. Res., 325: 47-51.

Febrer E, Mestres M, Caballín MR, Barrios L, Ribas M, GutiérrezEnríquez S, Alonso C, Ramón y, Cajal T, Francesc BJ (2008). Mitotic delay in lymphocytes from BRCA1 heterozygotes unable to reduce the radiation-induced chromosomal damage. DNA Repair (Amst)., 7 : 1907-1911.

Hassanein NM, Hasan WA, Hamed MR (2004). Effects of diclofenac, piroxicam and alpha-tocopherol on monoaminelymphopoietic interfacing in mice. Arzneimittelforschung, 54: 847-856.

Hoffer L, Thumb N (1984). Anti-inflammatorisch wirksame substanzen, ihre Wirkung auf DNA- synthese und reparature, in : Kuemmerte, Klinische Pharmakologie IV, 1-12, Eco. Med. Verlag.

Ito D, Matsumoto T (2010). Molecular mechanisms and function of the spindle checkpoint, a guardian of the chromosome stability. Adv. Exp. Med. Biol., 676: 15-26.

John AH (1973). A rapid in vivo test for chromosomal damage. Mut. Res., 18: 187-190.

Kawauchi S, Furuya T, Ikemoto K, Nakao M, Yamamoto S, Oka M, Sasaki K (2010). DNA copy number aberrations associated with aneuploidy and chromosomal instability in breast cancers. Oncol. Rep., 24: 875-883.

Klein G, Wottawa A (1975). Der Einfluss sogenannter Basistherapeuika und symptomatisch wirksamer antirheumatiko auf Enzyme der. DNA Reparatur, Acta. Med. Austriacu., 2: 153- 156.

Kullich W, Klein G (1986). Investigation of the influnce of nonsteroidal antirheumatic drugs on the rates of sister- chromatid exchange. Mutat. Res., 174: 131-134.

Kullich W, Hermann J, Klein G (1990). Cytogenetic studies of human lymphcytes under the influence of oxicams. Z. Rheumatol., 49: 77-81.

Levin ML (1988). Patterns of tubulo-intestinal Damage Associated with Nonsteroidal anti-infammatory drugs. Seminars in Nephrol., 8: 55-61.

Mitelman F (1983). Chromosome patterns in human cancer and leukemia In: Chromosome and Cancer from molecules to man. Edited by J.D. Rowley and J.E. vitamann, Bristol Myers cancer symposium, 5: 61-84, Academic Press, Orlando.

Moore RC (1981). Effects of 1-beta-D-arabinofuranosylcytosine on chromosomes, depending upon the cell cycle stage at the time of exposure. Mutat. Res., 83: 361-374.

Palmerini E, Fan K, Yang K, Risio M, Edelmann W, Lipkin M, Biasco G (2007). Piroxicam increases colon tumorigenesis and promotes apoptosis in Mlh1 +/- /Apc1638(N/+) mice. Anticancer Res., 27: 3807- 
3812.

Preston RJ, Av W, Bender MA, Brewen JG, Carrano AV, Heddle JA, McFee AF, Wolff S, Wassorn JS (1983). Mammalian in vivo and in vitro cytogenetic assays. A report of the Gene. Tox. Prog. Mut. Res., 87: 143- 188.

Riccardi VM (1977). The Genetic Approach to human Disease: Oxford University press, New York.

Sekiguchi M, Shirasaka M, Konno S, Kikuchi S (2008). Analgesic effect of percutaneously absorbed non-steroidal anti-inflammatory drugs: an experimental study in a rat acute inflammation model. BMC musculoskeletal Disorders. 31: 9:15

Sokal RR, Rohlf FJ (1981). Biometry: The Principles and Practice of Statistics in Biological Research. W.H. Freeman and Company, San Francisco, p. 859.
Wolff S, Rodin B, Cleavers JE (1977). Sister chromatid exchanges induced by mutagenic carcinogens in normal and xeroderma pigmentosum. Nature (London), 265: 347-349.

Yosida J, Amans DH (1965). Autosomal polymorphism in laboratory bred and wild Norway rats, Rattus norvegicus, found in Misima. Chromosoma, 16: 658-667.

Yoshida S, Ikehara N, Aoyama N, Shirasaka D, Sakashita M, Semba S, Hasuo T, Miki I, Morita Y, Tamura T, Azuma T, Yokozaki H, Kasuga M (2008). Relationship of BRAF mutation, morphology, and apoptosis in early colorectal cancer. Int. J. Colorectal. Dis., 23: 7-13. 